\title{
BMJ Open Trends in the incidence of testing for vitamin $D$ deficiency in primary care in the UK: a retrospective analysis of The Health Improvement Network (THIN), 2005-2015
}

\author{
Francesca L Crowe, ${ }^{1}$ Kate Jolly, ${ }^{1}$ Christine MacArthur, ${ }^{1}$ \\ Semira Manaseki-Holland, ${ }^{1}$ Neil Gittoes, ${ }^{2,3}$ Martin Hewison, ${ }^{4}$ Robert Scragg, ${ }^{3}$ \\ Krishnarajah Nirantharakumar ${ }^{1}$
}

To cite: Crowe FL, Jolly K, MacArthur C, et al. Trends in the incidence of testing for vitamin $D$ deficiency in primary care in the UK: a retrospective analysis of The Health Improvement Network (THIN), 2005-2015. BMJ Open 2019;9:e028355. doi:10.1136/ bmjopen-2018-028355

- Additional material is published online only. To view, please visit the journal online (http://dx.doi.org/10.1136/ bmjopen-2018-028355).

Received 4 December 2018 Revised 16 April 2019 Accepted 17 April 2019

\section{Check for updates}

(c) Author(s) (or their employer(s)) 2019. Re-use permitted under CC BY-NC. No commercial re-use. See rights and permissions. Published by BMJ.

${ }^{1}$ Institute of Applied Health Research, University of Birmingham, Birmingham, UK ${ }^{2}$ Centre for Endocrinology, Diabetes and Metabolism, University of Birmingham, Birmingham, UK

${ }^{3}$ School of Population Health, The University of Auckland, Auckland, New Zealand

${ }^{4}$ Institute of Metabolism and Systems, University of Birmingham, Birmingham, UK

Correspondence to Dr Francesca L Crowe; F.Crowe@bham.ac.uk

\section{ABSTRACT}

Objective To investigate trends in the incidence of testing for vitamin $D$ deficiency and the prevalence of patients with circulating concentrations of 25-hydroxyvitamin D $(25(\mathrm{OH}) \mathrm{D})$ indicative of deficiency $(<30 \mathrm{nmol} / \mathrm{L})$ between 2005 and 2015.

Design Longitudinal analysis of electronic health records in The Health Improvement Network primary care database.

Setting UK primary care.

Intervention None.

Participants The analysis included 6416709 participants aged 18 years and older.

Primary outcomes Incidence of having a blood test for vitamin D deficiency between 2005 and 2015, the prevalence with blood $25(\mathrm{OH}) \mathrm{D}<30 \mathrm{nmol} / \mathrm{L}$ and the effects of age, ethnicity and socioeconomic status on these measures were assessed.

Results After a mean follow-up time of 5.4 (SD 3.7) years, there were 210502 patients tested for vitamin D deficiency. The incidence of vitamin $D$ testing rose from 0.29 per 1000 person-years at risk (PYAR) $(95 \% \mathrm{Cl} 0.27$ to 0.31$)$ in 2005 to 16.1 per 1000 PYAR $(95 \% \mathrm{Cl} 15.9$ to 16.2$)$ in 2015 . Being female, older, non-white ethnicity and more economically deprived were all strongly associated with being tested. Onethird ( $n=69515$ ) had 25(OH)D $<30 \mathrm{nmol} / \mathrm{L}$, but the per cent deficient among ethnic minority groups ranged from $43 \%$ among mixed ethnicity to $66 \%$ in Asians. Being male, younger and more economically deprived were also all associated with vitamin $D$ deficiency $(p<0.001)$.

Conclusions Testing for vitamin $D$ deficiency increased over the past decade among adults in the UK. One-third of UK adults who had a vitamin $\mathrm{D}$ test performed in primary care were vitamin $\mathrm{D}$ deficient, and deficiency was much higher among ethnic minority patients. Future research should focus on strategies to ensure population intake of vitamin $\mathrm{D}$, particularly in at-risk groups, meets recommendations to reduce the risk of deficiency and need for testing.

There has been widespread interest in the research community of the health effects of vitamin $\mathrm{D}$ on the musculoskeletal system and
Strengths and limitations of this study

- This study includes a very large sample size with data up to the end of 2015.

- The clinical data in this study was collected prospectively.

- A large proportion of patients had missing data for ethnicity, which is an important determinant of being tested for vitamin D deficiency and being vitamin D deficient.

on conditions such as respiratory illness, ${ }^{1}$ cardiovascular disease, certain cancers and some neurological conditions. ${ }^{2}$ The resulting research and media attention generated from this interest has led to increased awareness among medical professionals and the general public of the potential role that vitamin D may have in maintaining good health. ${ }^{3}$

While the prevalence of low circulating concentrations of vitamin D (circulating 25-hydroxyvitamin D $(25(\mathrm{OH}) \mathrm{D})$ $<25 \mathrm{nmol} / \mathrm{L}$ ) among adults in the UK is around 20\% (National Diet and Nutrition Survey (NDNS)), ${ }^{4}$ the incidence of profound vitamin $\mathrm{D}$ deficiency in adults (osteomalacia) is rare. ${ }^{56}$ In the UK, national guidance for vitamin $\mathrm{D}$ deficiency is focused on population recommendations to supplement with vitamin $\mathrm{D}$ to prevent deficiency rather than testing and treating patients for vitamin D deficiency. Specifically, the Department of Health advises that all adults should consider taking a daily vitamin D supplement containing $100 \%$ of the recommended nutrient intake (RNI) of vitamin $\mathrm{D}$ of $10 \mu \mathrm{g}$ during the autumn and winter months, and adults at risk of developing vitamin D deficiency, such as people who are frail or housebound, in a care home 
or who cover up most of their skin when outdoors, should take a daily vitamin D supplement throughout the year. ${ }^{7}$ Further to this, recent clinical guidance issued by the National Osteoporosis Society (NOS) ${ }^{8}$ and the National Institute for Clinical Excellence ${ }^{9}$ states that patients should not be routinely tested for vitamin $\mathrm{D}$ deficiency.

Despite clinical guidance to restrict testing for vitamin $\mathrm{D}$ deficiency, there have been reports showing increasing rates of testing over the past decade in some parts of the UK. ${ }^{10} 11$ This has been accompanied by an increase in the number of prescriptions for vitamin D supplements (colecalciferol) and ensuing cost to the National Health Service (NHS).$^{12}$ It is not clear whether this increasing trend has continued after clinical guidance was published or whether these finding are true for the wider UK population and at-risk populations such as certain ethnic minority groups. The Health Improvement Network (THIN) database includes general practice (GP) records of over 11 million patients from over 600 UK GPs and offers the opportunity to examine incidence rates of patients tested for vitamin $\mathrm{D}$ deficiency over time. The objective of this analysis is to calculate the incidence rates of testing for vitamin $\mathrm{D}$ deficiency and the proportion of patients with circulating concentrations of $25(\mathrm{OH}) \mathrm{D}$ indicative of deficiency (ie, $<30 \mathrm{nmol} / \mathrm{L}$ ) and to examine whether this varies by year, socioeconomic status, sex, age or ethnicity of the patient.

\section{METHODS}

This study was an open cohort design using THIN primary care database that contains health records for $>11$ million patients from over $600 \mathrm{GPs}$ in the UK. The distribution of age, sex, prevalence of major medical conditions and mortality rates in the THIN cohort is generalisable to the UK population. ${ }^{13}$ The diagnoses in the THIN database are recorded using a hierarchical system called Read Codes, which are terms or short-phrases used to describe a health-related concept in GP records. ${ }^{14}$ Collection of data for THIN was approved by the South-East Multicentre Research Ethics Committee in 2003; under the terms of this approval, studies must undergo independent scientific review.

\section{Study population and period}

All data included in this study were from practices that met the acceptable mortality reporting and acceptable computer usage standards-measures of quality assurance for THIN data. ${ }^{15} 16$ Patients aged 18 years and older who were registered with a THIN practice contributing data between 1 January 2005 and 31 December 2015 were included in this analysis.

Read Codes for vitamin D tests were used as the outcome in this analysis; this included values for total vitamin D, 25-hydroxyvitamin D3 and 25-hydroxyvitamin D2. As many patients also had circulating concentrations of vitamin D tested on multiple occasions, only the first test was used in the analysis. Some patients had their first recorded test for vitamin $\mathrm{D}$ before the date of entry to THIN (1 January 2005) or before they turned 18 years and these patients were excluded from the analysis (online supplementary figure 1). Of the 210502 patients tested for vitamin D deficiency, $67607(32.1 \%)$ had at least one repeat test. Of these patients, $38 \%$ were retested $<6$ months from their first test and $63 \%$ were retested $<12$ months from their first test. On average, 67607 patients had circulating $25(\mathrm{OH}) \mathrm{D}$ retested 3.7 times.

\section{Patient and public involvement}

Patients or the public were not involved in setting the research question or the outcome measures, nor were they involved in developing plans for design or implementation of the study. Patients or the public were not asked to advise on interpretation or writing up of results. There are no plans to disseminate the results of the research to study participants, the relevant patient community or the public.

\section{Statistical analysis}

Age at entry was categorised into the following age groups: $18-24,25-34,35-44,45-54,55-64$ and $\geq 65$ years. Ethnicity was categorised into five groups based on those used in the UK Census: white, black or black British, mixed, Asian or Asian British and other (which includes Chinese, Middle Eastern and Pacific). Socioeconomic group was based on the Townsend deprivation score and divided into fifths with the lowest corresponding to the least deprived and the highest to the most deprived. Patients with missing data on ethnicity and Townsend deprivation score were assigned to a separate category for that variable and included in the regression analysis. The overall crude incidence of having a vitamin D test was estimated per 1000 person-years at risk (PYAR). This was calculated by totalling the number of patients with a first recording for a blood test for vitamin D deficiency between 2005 and 2015, and then dividing this by the number of person-years of follow-up of the patients for this period. Crude incidence rates by calendar year were calculated by restricting the person years of follow-up to each year in question. Person-years of follow-up were calculated from the date of entry to the THIN database which was the latest of the date of practice registration (plus 1 year), the date the practice met two predefined quality indicators for electronic data recording (acceptable mortality recoding and acceptable computer usage) or 1 January 2005 up to whichever came first: having a blood test for vitamin D deficiency, exit from the THIN database (transferred practice or died), the last date practice data were collected or 31 December 2015.

Poisson regression models were used to estimate incidence rate ratios (IRRs) and 95\% CIs of having a blood test for vitamin D deficiency by age group, ethnicity and socioeconomic group for men and women separately. The analyses were also repeated with restriction to those patients with at least 12 months of follow-up before the first vitamin D test. 
Logistic regression models were used to estimate the risk of vitamin $\mathrm{D}$ deficiency $(25(\mathrm{OH}) \mathrm{D}<30 \mathrm{nmol} / \mathrm{L})^{8}$ among participants who had a test for vitamin D deficiency according to age at blood test, ethnicity, socioeconomic group, year and month of blood test for men and women separately. This was undertaken after setting the value of $25(\mathrm{OH}) \mathrm{D}$ to $4 \mathrm{nmol} / \mathrm{L}$ for patients with $25(\mathrm{OH})$ $\mathrm{D}<5 \mathrm{nmol} / \mathrm{L}$, and setting the values of $25(\mathrm{OHD})$ to $201 \mathrm{nmol} / \mathrm{L}$ for patients with $25(\mathrm{OH}) \mathrm{D}>200 \mathrm{nmol} / \mathrm{L}$. To assess the influence of month of blood collection on blood concentrations of $25(\mathrm{OH}) \mathrm{D}$, a simple mathematical model of log-transformed blood vitamin $\mathrm{D}$ concentration by month of blood collection (as a categorical variable) was fitted. Standardised concentrations of $25(\mathrm{OH}) \mathrm{D}$ were calculated by adding the residuals from this model to the overall mean $\log$ blood vitamin $\mathrm{D}$ value and exponentiating these values, and the resulting $25(\mathrm{OH}) \mathrm{D}$ concentrations 'standardised for month of blood collection' were used for these analyses.

All statistical analyses were performed using Stata statistical software, V.15 (StataCorp, College Station, Texas, USA). Two-sided $\mathrm{p}$ values $<0.05$ were considered to be statistically significant.

This study cohort had 6416709 patients from 689 GP practices of whom 210502 had at least one blood test to measure 25(OH)D concentrations from 2005 to 2015 with a mean follow-up time of 5.4 (SD 3.7) years. The mean age of the men was 43 years and the mean age of the women was 44 years (table 1). Ethnicity was missing for more than half of the patients but among those with information on ethnicity, the majority were white (88.1\%), followed by Asian or Asian British $(4.7 \%)$, other $(3.2 \%)$, black or black British $(3.1 \%)$ and mixed $(0.9 \%)$.

Analysis of the time trends in the incidence of patients being tested for vitamin $\mathrm{D}$ deficiency show a strong upward trend from 2005 to 2015 (figure 1). The crude incidence rate increased from $0.29(95 \%$ CI 0.27 to 0.31$)$ per 1000 person-years in 2005 to 16.08 (95\% CI 15.92 to 16.23) per 1000 PYAR in 2015 (figure 1 and online supplementary table 1). The time trends in testing for vitamin D deficiency were much higher in women (2005: 0.46 (95\% CI 0.43 to 0.50 ) and 2015: 22.94 (95\% CI 22.68 to 23.21 per 1000 person-years) than in men (2005: 0.11 (95\% CI 0.10 to 0.13 ) and 2015: 9.30 (95\% CI 9.13 to 9.47 per 1000 person-years, online supplementary table 2 ).

The incidence rates and adjusted incidence rate ratios for vitamin $\mathrm{D}$ testing according to several demographic variables for men and women separately are shown in table 2. The incidence rate of vitamin $\mathrm{D}$ deficiency testing for men was 3.44 per 1000 PYAR (95\% CI 3.41 to 3.46)

Table 1 Descriptive characteristics of patients 18 years and older in the THIN database

\begin{tabular}{|c|c|c|c|}
\hline Characteristic & All & Men & Women \\
\hline Age at entry, years, mean (SD) & $43.3(19.0)$ & $42.6(18.1)$ & $44.0(19.7)$ \\
\hline \multicolumn{4}{|l|}{ Age categories (years), $n(\%)^{*}$} \\
\hline $18-24$ & $1269812(19.8 \%)$ & $619579(19.7 \%)$ & $650233(19.9 \%)$ \\
\hline $25-34$ & $1316390(20.5 \%)$ & $638713(20.3 \%)$ & $677677(20.7 \%)$ \\
\hline $35-44$ & $1180086(18.4 \%)$ & $612932(19.5 \%)$ & $567154(17.3 \%)$ \\
\hline $45-54$ & $901352(14.1 \%)$ & $465198(14.8 \%)$ & $436154(13.3 \%)$ \\
\hline $55-64$ & $755174(11.8 \%)$ & $378467(12.1 \%)$ & $376707(11.5 \%)$ \\
\hline$\geq 65$ & 993895 (15.5\%) & $426246(13.6 \%)$ & $567649(17.3 \%)$ \\
\hline \multicolumn{4}{|l|}{ Ethnicity, $n(\%)$} \\
\hline White & 2497397 (38.9\%) & $1168524(37.2 \%)$ & $1328873(40.6 \%)$ \\
\hline Asian or Asian British & $89180(1.4 \%)$ & $41597(1.3 \%)$ & $47583(1.5 \%)$ \\
\hline Black or black British & $24388(0.4 \%)$ & $11078(0.4 \%)$ & $13310(0.4 \%)$ \\
\hline Mixed & $132602(2.1 \%)$ & $70570(2.3 \%)$ & $62032(1.9 \%)$ \\
\hline Other & $91863(1.4 \%)$ & $41202(1.3 \%)$ & $50661(1.6 \%)$ \\
\hline Not known & $3581279(55.8 \%)$ & $1808164(57.6 \%)$ & $1773115(54.1 \%)$ \\
\hline \multicolumn{4}{|c|}{ Socioeconomic group, fifths, $n(\%)$} \\
\hline 1 (least deprived) & $1400936(21.8 \%)$ & $688591(21.9 \%)$ & 712345 (21.8\%) \\
\hline 2 & 1264659 (19.7\%) & $617290(19.7 \%)$ & 647369 (19.8\%) \\
\hline 3 & 1304497 (20.3\%) & $636675(20.3 \%)$ & $667822(20.4 \%)$ \\
\hline 4 & 1200411 (18.7\%) & 584967 (18.6\%) & $615444(18.8 \%)$ \\
\hline 5 (most deprived) & $854733(13.3 \%)$ & 425265 (13.5\%) & $429468(13.1 \%)$ \\
\hline Not known & 391473 (6.1\%) & 188347 (6.0\%) & $203126(6.2 \%)$ \\
\hline
\end{tabular}

${ }^{*}$ The per cent for some variables may not add to 100 due to rounding.

THIN, The Health Improvement Network. 


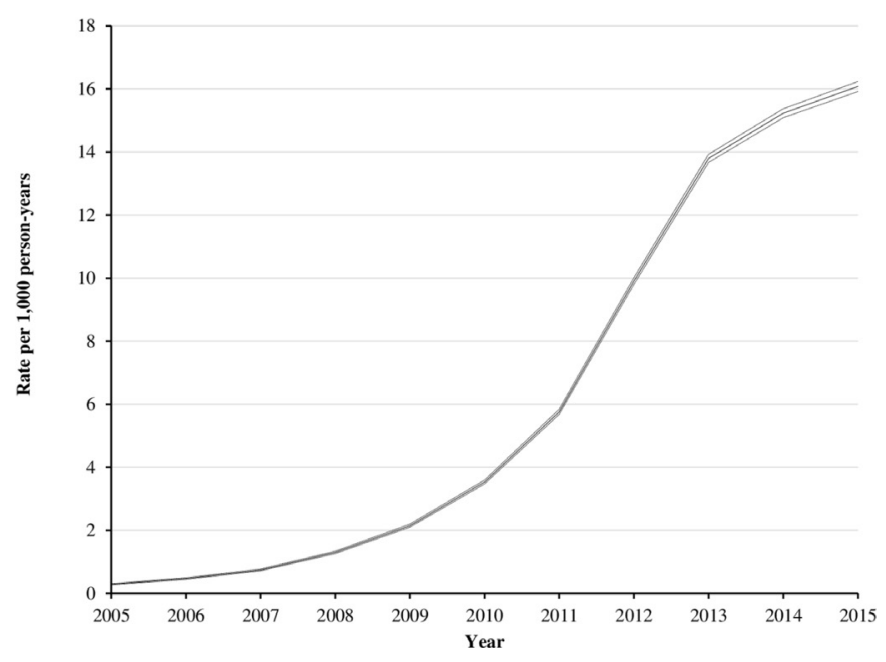

Figure 1 Crude incidence rate of testing of blood vitamin D levels in primary care in adults 18 years and older, 20052015. The solid line represents the incidence rate each year with the corresponding 95\% Cls (dashed lines).

and for women it was 8.77 per 1000 PYAR (95\% CI 8.73 to 8.82$)$. Asian women had the highest incidence rate of testing for vitamin D deficiency at 59.70 per 1000 PYAR (95\% CI 58.75 to 60.67$)$. Men aged $18-25$ years had the lowest incidence rate of testing for vitamin $\mathrm{D}$ deficiency at 1.82 per 1000 PYAR (95\% CI 1.77 to 1.87$)$. Older men were almost four times more likely to be tested for vitamin D deficiency compared with younger men. Older women were almost twice as likely to be tested for vitamin D deficiency compared with younger women. Compared with patients with white ethnicity, those who were Asian were over six times more likely to be tested for vitamin D deficiency (IRR=6.60, 95\% CI 6.42 to 6.79 for men and $\mathrm{IRR}=6.56,95 \%$ CI 6.44 to 6.68 for women). Patients whose ethnicity was black, mixed or other were two to three times more likely to be tested compared with those with white ethnicity. Those whose ethnicity was not known were less likely to be tested for vitamin D deficiency compared with patients whose ethnicity was white. Compared with patients who were the least deprived, the most deprived were about one and a half times more likely to be tested for vitamin D deficiency. Patients whose deprivation was not known were more than twice as likely to be tested for vitamin D deficiency compared with patients who were the least deprived. The unadjusted IRR for men and women are shown in online supplementary table 3 .

Table 3 shows the prevalence and OR of having blood concentrations of $25(\mathrm{OH}) \mathrm{D}$ indicative of deficiency (after

Table 2 Incidence of testing for vitamin D deficiency by sociodemographic factors for men and women*

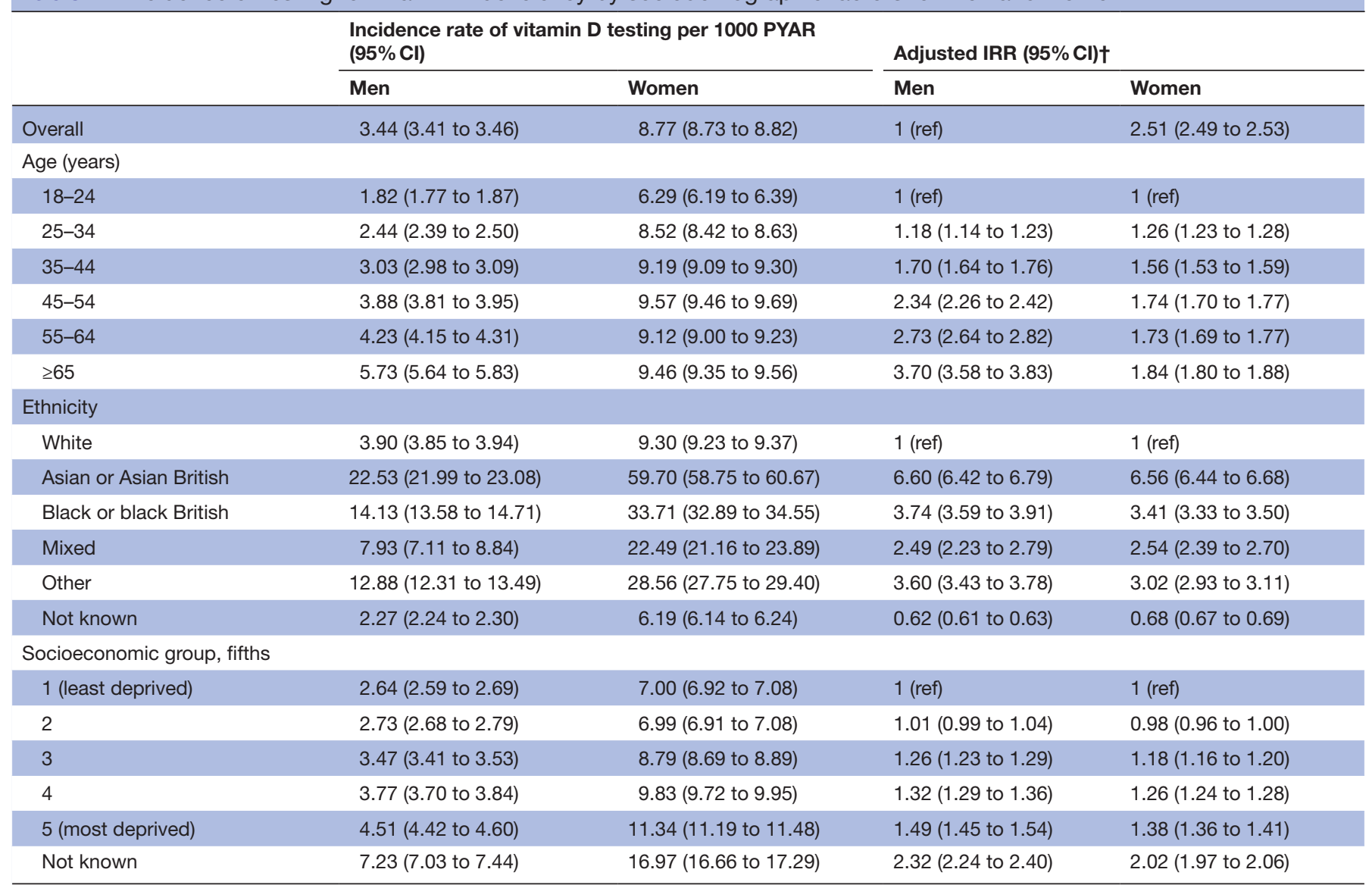

${ }^{*}$ Results are presented separately for men and women because of a statistically significant interaction between sex and age group ( $\left.p<0.0001\right)$. †Adjusted for age group, ethnicity and socioeconomic group where appropriate.

IRR, incidence rate ratio; PYAR, person-years at risk. 
Table 3 Associations between sociodemographic characteristics and having circulating 25 -hydroxyvitamin $D<30 \mathrm{nmol} / \mathrm{L}$ for men and women ${ }^{*} \dagger$

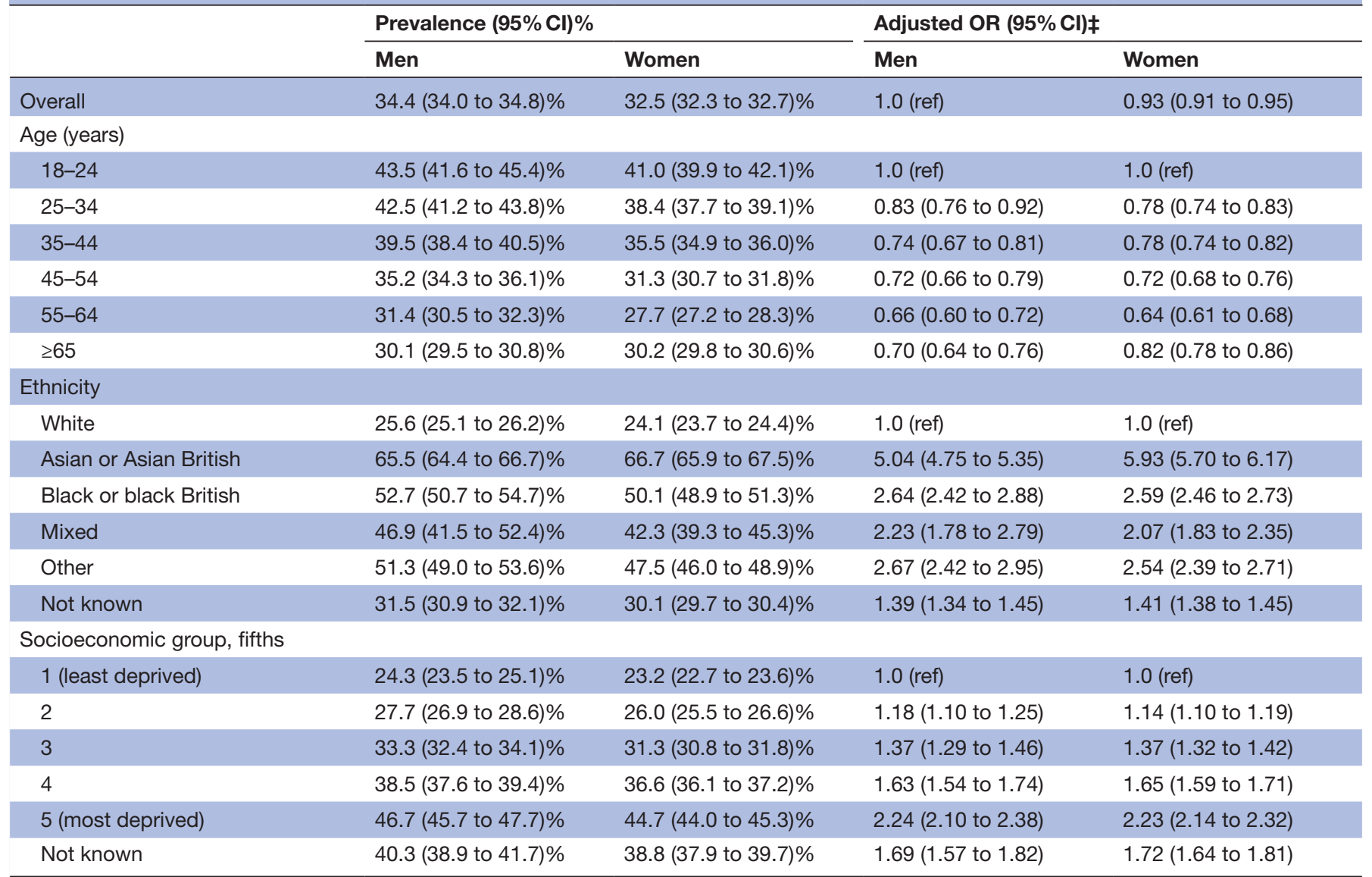

${ }^{*}$ Results are presented separately for men and women because of a statistically significant interaction between sex and age group $(p<0.0001)$. †Corrected for month of blood collection.

$\ddagger$ Adjusted for age group, ethnicity and socioeconomic group where appropriate.

standardising for month of blood collection) by age, ethnicity and socioeconomic status for men and women in analyses restricted to those patients who were tested for vitamin D deficiency. One-third of patients had circulating concentrations of $25(\mathrm{OH}) \mathrm{D}<30 \mathrm{nmol} / \mathrm{L}$. Women were $7 \%$ less likely to be vitamin $\mathrm{D}$ deficient compared with men ( $\mathrm{OR}=0.9395 \% \mathrm{CI} 0.91$ to $0.95, \mathrm{p}<0.001)$. There was a lower risk of being deficient with older age; men and women 65 years and older had a $30 \%$ and $18 \%$ lower risk of being vitamin $\mathrm{D}$ deficient compared with patients aged 18-25 years, respectively. Compared with white patients, patients who were black, mixed or other ethnicity had over two times the risk of having blood vitamin D concentrations indicative of deficiency, and Asian patients had more than five to almost six times the risk of being vitamin D deficient. Patients who were the most deprived had more than twice the risk of being vitamin $\mathrm{D}$ deficient compared with those who were the least deprived ( $\mathrm{OR}=2.24,95 \%$ CI 2.10 to 2.38 for men and $\mathrm{OR}=2.23,95 \%$ CI 2.14 to 2.32 for women).

Results in figure 2 show the proportion of patients with circulating concentrations of $25(\mathrm{OH}) \mathrm{D}<30 \mathrm{nmol} / \mathrm{L}$ by month and year of blood collection. There was a strong effect of month of blood collection on vitamin D deficiency with the highest per cent being tested in January to March and the lowest per cent tested in July to September each year. After standardising $25(\mathrm{OH}) \mathrm{D}$ concentrations

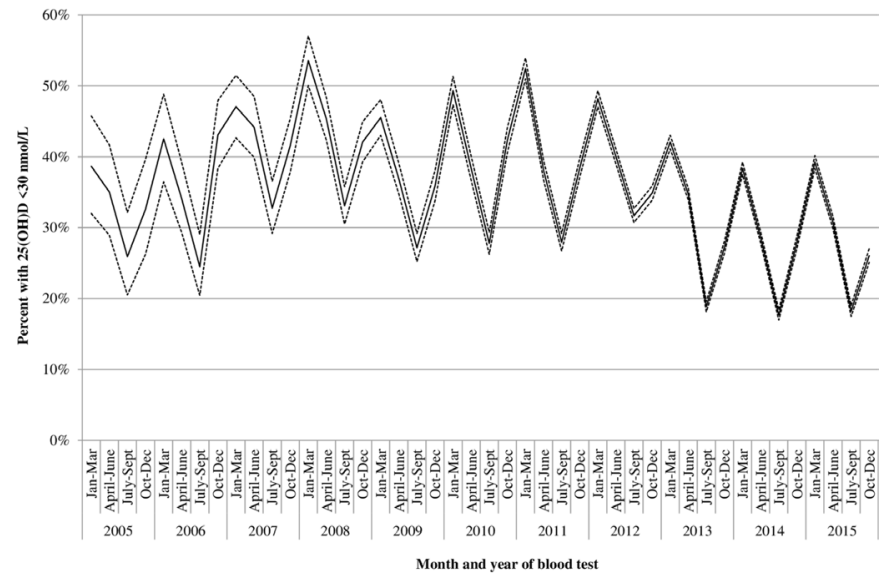

Figure 2 Per cent of patients with circulating concentrations of 25 -hydroxyvitamin $\mathrm{D}(25(\mathrm{OH}) \mathrm{D})<30 \mathrm{nmol} / \mathrm{L}$ by month and year of blood collection, 2005-2015. Per cent each quarter of the year with the corresponding 95\% Cls (dashed lines). 
for month of blood collection, and adjusting for sex, age, ethnicity and socioeconomic status, there was a statistically significant association between the year of blood collection and the per cent of patients with vitamin D deficiency; over time, patients tested for vitamin D deficiency had a slightly lower risk of being vitamin D deficient (OR per year $=0.913,95 \%$ CI 0.909 to 0.917 ).

In sensitivity analysis, it made little material difference to the risk of being tested for vitamin D deficiency after censoring the first year of follow-up (online supplementary table 4). Results in online supplementary table 5 show the distribution of patients according to categories of circulating concentrations of $25(\mathrm{OH}) \mathrm{D}$ after standardising blood concentrations of vitamin $\mathrm{D}$ for month of blood collection; $33 \%$ had $25(\mathrm{OHD})<30 \mathrm{nmol} / \mathrm{L}, 30 \%$ had concentrations between 30 and $50 \mathrm{nmol} / \mathrm{L}, 23 \%$ had concentrations between 50 and $75 \mathrm{nmol} / \mathrm{L}$ and $14 \%$ had concentrations of $25(\mathrm{OH}) \mathrm{D} \geq 75 \mathrm{nmol} / \mathrm{L}$. The geometric mean circulating concentrations of $25(\mathrm{OH}) \mathrm{D}$ for men and women by age group, ethnicity and socioeconomic status are shown in online supplementary table 6 . The geometric mean concentration of $25(\mathrm{OH}) \mathrm{D}$ was highest among white men $(41.9,95 \%$ CI 41.6 to $42.2 \mathrm{nmol} / \mathrm{L})$ and white women (44.0, 95\% CI 43.8 to $44.2 \mathrm{nmol} / \mathrm{L}$ ). Asian men and women had the lowest mean concentrations of $25(\mathrm{OH}) \mathrm{D}(23.9,95 \% \mathrm{CI} 23.6$ to $24.3 \mathrm{nmol} / \mathrm{L}$ and 23.3, $95 \%$ CI 23.1 to $23.5 \mathrm{nmol} / \mathrm{L}$, respectively).

\section{DISCUSSION}

There was more than a 50 -fold increase in the incidence of testing for vitamin D deficiency in UK primary care between 2005 and 2015. Patients belonging to ethnic minority groups and those who were more economically deprived had a greater risk of being tested for vitamin D deficiency and were more likely to have blood concentrations of $25(\mathrm{OH}) \mathrm{D}$ indicative of deficiency. On the other hand, patients older than 65 years were almost twice as likely to be tested for vitamin D deficiency but were less likely to have vitamin D deficiency compared with younger patients. Over one-third of patients tested for vitamin $\mathrm{D}$ deficiency had sufficient blood concentrations of $25(\mathrm{OH}) \mathrm{D}$ and this was more common among patients who were older, white and the least deprived.

This is the first study in the UK to calculate the incidence of testing for vitamin D deficiency among adults over time. Others have shown a dramatic increase in the rates of testing for vitamin $\mathrm{D}$ among children in primary care from 2008 to 2014 and have also shown that children with Asian, black, mixed and other ethnicity were more likely to be tested compared with white children. ${ }^{17}$ Zhao et $a l^{11}$ showed that the number of requests for vitamin D tests among adult patients in primary care practices in Liverpool increased substantially from 2007 to 2012 as others have demonstrated in other parts of the UK, ${ }^{10}$ but neither of these reports in adults included incidence rates for vitamin D testing by ethnicity or socioeconomic status.
Results from the $2012 / 2013$ to $2013 / 2014$ NDNS showed that $22 \%$ of men and $15 \%$ of women aged 19-64 years had blood concentrations of $25(\mathrm{OH}) \mathrm{D}<25 \mathrm{nmol} / \mathrm{L}^{4}{ }^{4}$ This analysis showed slightly higher rates of vitamin $\mathrm{D}$ deficiency of $34 \%$ among men and $33 \%$ among women. This is not surprising given there was a higher proportion of patients tested for vitamin D deficiency who were more likely to have lower blood concentrations of vitamin D than the general population (such as patients from ethnic minority groups $)^{18}$ and choice of a higher cut point to define vitamin $\mathrm{D}$ deficiency $(<30 \mathrm{nmol} / \mathrm{L})$ in this analysis. There is a lack of global consensus regarding the choice of cut points used to define vitamin $\mathrm{D}$ deficiency meaning that it can often be difficult to quantify the extent of vitamin $\mathrm{D}$ deficiency and compare rates across studies. ${ }^{80-22}$ The most recent results from the NDNS also showed a lower prevalence of vitamin D deficiency among adults over 65 years compared with younger adults. ${ }^{4}$ The finding of higher rates of testing for vitamin $\mathrm{D}$ deficiency but lower rates of deficiency in older women could be because these women were more likely to be diagnosed with osteoporosis and have vitamin D deficiency corrected before beginning treatment. ${ }^{823}$ If they were taking vitamin $\mathrm{D}$ supplements before being tested for vitamin $\mathrm{D}$ deficiency then this would explain the lower rates of vitamin D deficiency. Although it should be noted that NOS does not recommend routine testing for vitamin D deficiency in patients who are co-prescribed treatment for osteoporosis and a vitamin D supplement. ${ }^{8}$

There was no indication that the incidence rates of testing for vitamin $\mathrm{D}$ deficiency showed any sign of decreasing after clinical guidance was published in 2013 recommending patients should not be routinely tested for vitamin D deficiency in primary care, although the incidence curve suggested a slight inflection point in 2013. While the absolute number of patients with blood concentrations of $25(\mathrm{OH}) \mathrm{D}<30 \mathrm{nmol} / \mathrm{L}$ increased over time, peaking in 2013 at over 13000 , there was a slight decrease in the per cent of patients with vitamin D deficiency from 2005 to 2015. If more test laboratories replaced automated immunoassays with the gold standard tandem mass spectrometry (which reads higher values) over time, this may have reduced the proportion of patients with vitamin D deficiency. ${ }^{24}$ Nevertheless, an analysis of primary care records in Liverpool where $25(\mathrm{OH}) \mathrm{D}$ was measured using tandem mass spectrometry also showed a reduction in the proportion of patients diagnosed with vitamin D deficiency from 2007 to $2012 .{ }^{11}$ Therefore, an alternative explanation for the small decrease in the proportion of patients with vitamin $\mathrm{D}$ deficiency over time could be due to the large increase in the number of patients undergoing testing for vitamin D deficiency, suggesting that testing for vitamin $\mathrm{D}$ deficiency is being performed less selectively over time.

Other countries such as Australia, ${ }^{25}$ Canada $^{26}$ and France ${ }^{27}$ have also shown a substantial increase in the number of tests for vitamin $\mathrm{D}$ deficiency in recent times. In response to the large number of tests for vitamin $\mathrm{D}$ deficiency and rising cost to the healthcare service in Alberta, Canada, the laboratory services division developed an additional 
tool in the laboratory ordering system, whereby clinicians had to identify the medical indication(s) for testing blood $25(\mathrm{OH}) \mathrm{D}$ concentrations. Nine months after this criteria-based approach to ordering tests for vitamin $\mathrm{D}$ levels was introduced, the number of vitamin D tests fell by $92 \%$ (from around 250000 to 20000 ), greatly reducing the number of unnecessary tests for $25(\mathrm{OH}) \mathrm{D}$ while not missing testing blood $25(\mathrm{OH}) \mathrm{D}$ in patients with clinically relevant indications. ${ }^{26}$

The implementation of population-based approaches to ensure adequate intake of vitamin $\mathrm{D}$ is another strategy that may contribute to a reduction in the need to test for vitamin $\mathrm{D}$ deficiency. This approach has been adopted in Finland where the fortification of liquid dairy products and fat spreads with higher amounts of vitamin D in combination with vitamin $\mathrm{D}$ supplementation has greatly reduced the number of adults with low concentrations of $25(\mathrm{OH}) \mathrm{D} .{ }^{28} \mathrm{In}$ the UK, an RNI for vitamin D of $10 \mu \mathrm{g} /$ day has been set to ensure that $97.5 \%$ of the population achieves blood concentrations of $25(\mathrm{OH}) \mathrm{D}>25 \mathrm{nmol} / \mathrm{L}$ all year round. ${ }^{22}$ However, the majority of the population are not meeting this recommendation with the mean intake of vitamin $\mathrm{D}$ from foods in adults 19 years and older in the most recent NDNS was only 28\%-33\% of the RNI. ${ }^{4}$ Public Health England recommends that all adults should consider taking a vitamin D supplement, but only a small proportion of adults follow this guidance; $30 \%$ of adults reported taking a supplement that might contain vitamin D during the past year (ie, cod liver oil and other fish oils, calcium only or with vitamin $\mathrm{D}$, multivitamins (no minerals) or multivitamins and minerals). ${ }^{29}$ Public health strategies that encourage more widespread fortification of staple foods with vitamin $D^{30} 31$ in combination with provision of vitamin D supplements (particularly to at-risk groups) will ensure the majority of the population meet this RNI which in turn will lower the prevalence of vitamin $\mathrm{D}$ deficiency in the population and reduce the need for patients to be tested for vitamin D deficiency in primary care.

Strengths of this study include a very large sample size with data up to the end of 2015 and use of a database with clinical data that is collected prospectively. Limitations include a large proportion of patients who had missing data for ethnicity, which is an important determinant of being tested for vitamin D deficiency and being vitamin $\mathrm{D}$ deficient. Individuals with missing data on ethnicity were included in a separate category and these individuals had lower rates of testing for vitamin D deficiency but higher rates of deficiency compared with those whose ethnicity was white. Therefore, it is possible that the true influence of ethnicity on vitamin D testing and deficiency was overestimated or underestimated.

In summary, results from this analysis show a 50-fold increase in testing for vitamin $\mathrm{D}$ deficiency among adults in UK primary care from 2005 to 2015. Although these results showed that patients at risk of vitamin D deficiency are more likely to be tested and be vitamin D deficient, public health strategies that prevent these at-risk groups from developing vitamin D deficiency may be a more cost-effective way to reduce the burden of vitamin D deficiency. ${ }^{32}$ Future research should focus on strategies to reduce the need to test for vitamin $\mathrm{D}$ deficiency in primary care while ensuring that the intake of vitamin D meets the recommended levels to reduce the risk of deficiency in the population.

Contributors FLC, KJ, CM, SM-H, NG, MH, RS and KN made substantial contributions to the conception and design, acquisition of data or analysis and interpretation of data. All authors drafted the article or revised it critically for important intellectual content. All authors approved the final version of the manuscript to be published. FLC is the guarantor of this work.

Funding The authors have not declared a specific grant for this research from any funding agency in the public, commercial or not-for-profit sectors.

Competing interests None declared.

Patient consent for publication Not required.

Ethics approval Ethics approval was obtained by Scientific Review Committee (for the use of THIN data) in September 2017 (SRC reference 17THIN088).

Provenance and peer review Not commissioned; externally peer reviewed.

Data sharing statement The dataset on which the conclusions of the paper rely are available on request from the authors.

Open access This is an open access article distributed in accordance with the Creative Commons Attribution Non Commercial (CC BY-NC 4.0) license, which permits others to distribute, remix, adapt, build upon this work non-commercially, and license their derivative works on different terms, provided the original work is properly cited, appropriate credit is given, any changes made indicated, and the use is non-commercial. See: http://creativecommons.org/licenses/by-nc/4.0/.

\section{REFERENCES}

1. Martineau AR, Jolliffe DA, Hooper RL, et al. Vitamin D supplementation to prevent acute respiratory tract infections: systematic review and meta-analysis of individual participant data. BMJ 2017;356:i6583.

2. Theodoratou E, Tzoulaki I, Zgaga L, et al. Vitamin D and multiple health outcomes: umbrella review of systematic reviews and meta-analyses of observational studies and randomised trials. BMJ 2014;348:g2035.

3. Moon RJ, Curtis EM, Davies JH, et al. Seasonal variation in Internet searches for vitamin D. Arch Osteoporos 2017;12:28.

4. Bates B, Lennox A, Prentice A, et al. National diet and nutrition survey results from years 5 and 6 (combined) of the Rolling Programme (2012/2013 - 2013/14). London: Department of Health, 2016.

5. Lips P. Vitamin D deficiency and secondary hyperparathyroidism in the elderly: consequences for bone loss and fractures and therapeutic implications. Endocr Rev 2001;22:477-501.

6. Ramagopalan SV, Goldacre R, Disanto G, et al. Hospital admissions for vitamin $D$ related conditions and subsequent immune-mediated disease: record-linkage studies. BMC Med 2013;11: 171.

7. NHS Choices. Vitamin D. http://www.nhs.uk/Conditions/vitaminsminerals/Pages/Vitamin-D.aspx (Accessed 28 Feb 2017).

8. Francis R, Aspray T, Gittoes N, et al. Vitamin D and bone health a practical clinical guidelines for patient management: National Osteoporosis Society, 2013.

9. National Institute for Health and Care Excellence. Vitamin D deficiency in adults - treatment and prevention. https://cks.nice. org.uk/vitamin-d-deficiency-in-adults-treatment-and-prevention\#! scenario:1 (Accessed 26 Mar 2017).

10. Sattar N, Welsh $P$, Panarelli $M$, et al. Increasing requests for vitamin D measurement: costly, confusing, and without credibility. Lancet 2012;379:95-6.

11. Zhao S, Gardner K, Taylor W, et al. Vitamin D assessment in primary care: changing patterns of testing. London J Prim Care 2015;7:15-22.

12. Prescribing \& Medicines Team, Health and Social Care Information Centre. Prescription cost analysis England 2015: Health and Social Care Information Centre, 2016.

13. Blak B, Thompson M, Dattani H, et al. Generalisability of the Health Improvement Network (THIN) database: demographics, chronic 
disease prevalence and mortality rates. J Innov Health Inform 2011;19:251-5.

14. Booth N. What are the Read Codes? Health Libr Rev 1994;11:177-82.

15. Maguire A, Blak BT, Thompson M. The importance of defining periods of complete mortality reporting for research using automated data from primary care. Pharmacoepidemiol Drug Saf 2009;18:76-83.

16. Horsfall L, Walters K, Petersen I. Identifying periods of acceptable computer usage in primary care research databases. Pharmacoepidemiol Drug Saf 2013;22:64-9.

17. Basatemur E, Hunter R, Horsfall L, et al. Costs of vitamin D testing and prescribing among children in primary care. Eur J Pediatr 2017;176:1405-9.

18. Farrar MD, Kift R, Felton SJ, et al. Recommended summer sunlight exposure amounts fail to produce sufficient vitamin D status in UK adults of South Asian origin. Am J Clin Nutr 2011;94:1219-24.

19. Kift R, Berry JL, Vail A, et al. Lifestyle factors including less cutaneous sun exposure contribute to starkly lower vitamin D levels in U.K. South Asians compared with the white population. $\mathrm{Br} J$ Dermatol 2013;169:1272-8.

20. Holick MF, Binkley NC, Bischoff-Ferrari HA, et al. Evaluation, treatment, and prevention of vitamin $D$ deficiency: an Endocrine Society clinical practice guideline. J Clin Endocrinol Metab 2011;96:1911-30.

21. Ross AC, Manson JE, Abrams SA, et al. The 2011 report on dietary reference intakes for calcium and vitamin D from the Institute of Medicine: what clinicians need to know. J Clin Endocrinol Metab 2011;96:53-8.

22. Department of Health. Scientific Advisory Committee on Nutrition. Vitamin D and Health, 2016.

23. van der Velde RY, Wyers CE, Teesselink E, et al. Trends in oral antiosteoporosis drug prescription in the United Kingdom between 1990 and 2012: Variation by age, sex, geographic location and ethnicity. Bone 2017;94:50-5.

24. Roth HJ, Schmidt-Gayk H, Weber H, et al. Accuracy and clinical implications of seven 25-hydroxyvitamin D methods compared with liquid chromatography-tandem mass spectrometry as a reference. Ann Clin Biochem 2008;45:153-9.

25. Bilinski K, Boyages S. Evidence of overtesting for vitamin D in Australia: an analysis of 4.5 years of Medicare Benefits Schedule (MBS) data. BMJ Open 2013;3:e002955.

26. Ferrari R, Prosser C. Testing Vitamin D levels and choosing wisely. JAMA Intern Med 2016;176:1019-20.

27. Caillet P, Goyer-Joos A, Viprey M, et al. Increase of vitamin D assays prescriptions and associated factors: a population-based cohort study. Sci Rep 2017;7:10361.

28. Raulio S, Erlund I, Männistö S, et al. Successful nutrition policy: Improvement of Vitamin D intake and status in Finnish adults over the last decade. Eur J Public Health 2017;27:268-73.

29. Bates B, Lennox A, Prentice A, et al. National diet and nutrition survey headline results from years 1,2 and 3 (combined) of the Rolling Programme (2008/2009-2010/11). London: Department of Health, 2012.

30. Allen RE, Dangour AD, Tedstone AE, et al. Does fortification of staple foods improve vitamin $D$ intakes and status of groups at risk of deficiency? A United Kingdom modeling study. Am J Clin Nutr 2015;102:338-44.

31. Pilz S, März W, Cashman KD, et al. Rationale and plan for vitamin $\mathrm{D}$ food fortification: a review and guidance paper. Front Endocrinol 2018;9.

32. Aguiar M, Andronis L, Pallan M, et al. Preventing vitamin D deficiency (VDD): a systematic review of economic evaluations. Eur J Public Health 2017;27:292-301. 